REVISTA CHILENA DE LITERATURA

Abril 2009, Número 74, 79 - 98

\title{
DE ARMARIOS Y BIBLIOTECAS: MASCULINIDAD Y TRADICIÓN LITERARIA CHILENA EN LA NARRATIVA DE ALBERTO FUGUET ${ }^{1}$
}

\author{
Cristián Opazo \\ Pontificia Universidad Católica de Chile \\ cmopazo@uc.cl \\ “. . y y no es raro que desde chico el niño escuche al coro de tías atacar \\ a su padre por borracho, flojo y desaparecido". \\ -Alberto Fuguet subrayando a Sonia Montecino \\ “. . . uno lee para vivir otras vidas, vidas que jamás podría -o se \\ atrevería- a vivir en la realidad."
}

-Alberto Fuguet, "Leer”

\section{RESUMEN / ABSTRACT}

La tesis de este ensayo postula que la narrativa de Alberto Fuguet puede ser leída como un proyecto escriturario que propone una (nueva) estrategia retórica por la cual representar los desvíos del género sexual. Según este modus operandi, en las narraciones de Fuguet, tanto el acto de reprimir como el de explicitar los desvíos de la masculinidad, se ejecutan a través de un juego de citas a la tradición literaria chilena. En los textos de José Donoso, Jorge Edwards y Alfredo Gómez Morel, entre otros, los narradores personajes de Fuguet encuentran un conjunto de figuras retóricas que les permite decir su desvío, pero de manera oblicua; es decir, cifrando la voluptuosidad de sus deseos en la lengua culturalmente prestigiosa del Canon de las Letras de Chile. Dentro de este contexto, este ensayo pesquisa las citas que los primeros

1 Este trabajo forma parte del Proyecto Fondecyt 1051005 "Memorias del 2000: narrativa chilena y globalización". 
trabajos de Fuguet (Sobredosis y Mala onda) hacen de Casa de campo y El jardín de al lado, de José Donoso, y El río, de Alfredo Gómez Morel.

Palabras clave: Alberto Fuguet, masculinidad, tradición-literaria-chilena, José Donoso, novela-chilena siglo-XX.

This essay proposes that Alberto Fuguet's narrative may be read as a writing project with a (new) rhetorical strategy by which various sexual deviances may be represented. By this modus operandi, in Fuguet's stories, both manifestation and repression of male deviance are made explicit by way of a 'quotation game' in the field of chilean literary tradition. The narrators in his texts find in the narrative of José Donoso, Jorge Edwards and Alfredo Gómez Morel, among others, a corpus of rhetorical figures which allow them to make their deviance explicit in an oblique way; that is, to condense their voluptous desire in the prestigious language of the Chilean Literary Canon. Within this context, this essay explores the quotations of Donoso's Casa de Campo and El Jardin de al lado, and those quotations of Alfredo Garcia Morel's El rio present in Alberto Fuguet's first works (Sobredosis y Mala Onda).

KEY WORDS: Alberto Fuguet, masculinity, chilean literary tradition, José Donoso, XXth century chilean novel.

\section{ESCENA 1. JUGAR (A LAS ESCONDIDAS) EN LA BIBLIOTECA}

Ni la portada que el Newsweek le consagra en su edición latinoamericana del 6 de mayo de 2002, ni el elogio que Oprah Winfrey dedica a la traducción inglesa de su novela The Movies of My Life (New York: Harper Collins 2003), en uno de sus "Book Club" del año 2004, ni siquiera, su temprana pose de world citizen que sabe "que Seattle es como Puerto Montt o Castro con plata" (Primera 196), y que allí "el café no se asemeja al jugo de paraguas típicamente yanqui ni a los cortados de Tavelli [de Santiago de Chile]" (Primera 196): nada de lo que se diga sobre la imagen pública del autor (modelo de la cultura libresca de la era global) debería evitar que, a los ojos del lector voyeur, la narrativa del chileno Alberto Fuguet (Santiago 1964) sea considerada un proyecto escriturario que -ante todo- propone una (nueva) gramática de la masculinidad. $\mathrm{O}$, de manera más puntual, una (nueva) retórica literaria por la cual callar y decir los desvíos del género sexual ${ }^{2}$.

2 Entiendo el género sexual desde la perspectiva de Judith Butler en Undoing Gender. Allí, ella opina que "[if] a gender is a kind of doing, and incessant activity performed, in part without one's knowing and without one's willing, it is not for that reason automatic or 
Desde mi perspectiva, entonces, los rasgos distintivos de los narradores/ personajes de los relatos de Fuguet no serían ni sus bitácoras plagadas de referencias a esos no-lugares producidos por la súper-modernidad (aeropuertos, centros comerciales, hoteles) ${ }^{3}$, ni sus hablas fronterizas, a medio camino entre el inglés de Brett Easton Ellis o S. E. Hinton, y el español de MTV Latino ${ }^{4}$. Lo que efectivamente distinguiría a estos genuinos pasajeros en tránsito -sugiero- sería la manera desviada, fallida o tortuosa, en que "se hacen hombres".

Esta presunción no resulta azarosa; el lector ya habrá notado que, en el nivel de los enunciados, los narradores/ personajes de Fuguet exhiben deseos furibundos de aniquilación simbólica del padre, trastornos que les impiden forjar relaciones afectivas más duraderas que las masturbaciones adolescentes y, por qué no decirlo, una retórica que mienta al otro femenino desde estereotipos que contrastan con la "profundidad" de sus caracterizaciones del cuerpo masculino ${ }^{5}$. Además de las evidencias textuales conocidas por

mechanical, it is a practice of improvisation within a scene of constraint. Moreover, one does not "do" one's gender alone. One is always is "doing" with or for another, even if the other is only imaginary" (1). Y, más adelante, apostilla: “. . .the terms that make up one's own gender are, from the start, outside one self in a sociality that has no single author and that radically contest the notion of authorship" (1). En suma, si aceptamos que la construcción del género es un performance que tiene lugar within a scene of constraint, en este ensayo, la pregunta por el género será inquisición por las tensiones que se suscitan, en la escena de lectura/ escritura literaria, entre el sujeto de la enunciación y las miradas (censoras o autorizadoras) de los académicos, críticos periodísticos y lectores casuales.

3 Las locaciones dilectas de las novelas de Fuguet son, justamente, no-lugares: en Mala onda, el protagonista llega a Santiago a bordo de un DC-10 de Varig; en Tinta roja, el narrador rescribe su vida desde un avión que sobrevuela el aeropuerto Raleigh/ Durham; y, en Las películas de mi vida, la anécdota se torna compleja "[a] bordo del vuelo Lan Chile 511, Boing 767, tramo SCL/ LIM" (51).

4 Desde 1987 (año en que se afianza como columnista de la revista Apsi), Fuguet introduce, sistemáticamente, novedosos anglicismos al español de Chile: bomb (Rev. Wikén, 1990), cult (Rev. Mundo, 1988), o freaks (Rev. CEP, 1992). A propósito, véase su antología de crónicas periodísticas Primera parte.

5 Anótense algunos ejemplos consabidos: en Mala onda, el protagonista solo reconoce a su padre cuando lo ve "acurrucado como un niño" (372) en la cama de un prostíbulo; en "Los muertos vivos", las escasas experiencias sexuales no-traumáticas, son las jugarretas entre púberes: "[e]l único descartuchado del grupo era el Drago" (29), "[a]sí que mientras tanto las Playboy y Penthouse del Rocky, los videos pornos del papá del Pipe, papel confort, quién se va cortado primero, quien lanza el chorro más lejos" (30). En fin, "En pelando a Rocío", 
todos los incondicionales de Fuguet $-\mathrm{y}$, remarco, manifestadas en el nivel del enunciado- mi deseo aquí es buscar nueva evidencia textual; pero, esta vez, en el nivel de la enunciación. Intuyo que aquello que en el enunciado (literalmente la anécdota) puede ser comprendido como representación de un "Complejo de Edipo" no resuelto, en el nivel de la enunciación (la manera de decir esas anécdotas), revela una compleja economía del deseo masculino y su consecuente represión.

Propongo - en suma- que en las narraciones de Fuguet, tanto el acto de callar (reprimir) como el de decir (liberar) los desvíos de la masculinidad, se ejecutan a través de un juego de citas y censuras al archivo literario chileno. Me explico: las glosas y las tachaduras a los libros de José Donoso, Jorge Edwards o Alfredo Gómez Morel inscritas en los relatos de Fuguet, ofrecen a sus personajes un conjunto de figuras retóricas, de citas, de máscaras y de disfraces que les permite decirse "desviados," "homosexuales (de clóset)," "misóginos," "perdidos," pero de manera oblicua, en clave; esto es, cifrando la voluptuosidad de sus deseos (a veces inconfesables), en la lengua decorosa, mesurada, naturalizada o socialmente prestigiosa del Canon de las Letras de Chile ("uno lee para vivir otras vidas. ..")

Apuesto, en breve, que en plena era global, de manera paradójica, la Biblioteca de la Nación es el espacio donde -cual armario- los personajes de Fuguet logran esconder o disimular esas conductas muy otras que no se dejan contar en la lingua franca de la Transición a la Democracia?

relato donde quien habla es una mujer, la narradora confiesa: "igual hubiera votado que sí, yo cacho, no tengo nada contra el gobierno, en realidad no pesco, a decir verdad, a mi Pinocho [Pinochet] no me ha hecho nada" (59-60).

6 Es pertinente reparar que, en cada uno de los escritos de Fuguet, se exhibe una estilización o una polémica con algún narrador criollo al que, cuando no se le unge como padre putativo, se le recrimina como responsable de la orfandad de nuestros tiempos. En Sobredosis, hay guiños al José Donoso de El jardín de al lado; en Mala onda, un ajuste de cuentas con el Donoso de Casa de campo; en Tinta roja, un homenaje a El río, de Alfredo Gómez Morel, e Hijo de Ladrón, de Manuel Rojas; en Primera Parte, una loa al José Donoso cinéfilo y cronista; y, por último, en Apuntes autistas, nuevas pullas para Donoso e inesperados elogios para los Edwards: Joaquín y Jorge.

7 La crítica ha descuidado las filiaciones literarias de la escritura de Fuguet: con excepción de María Nieves Alonso (quien dedica un acucioso estudio a la relación entre Mala onda, de Fuguet, y la novela chilena del siglo XIX), el resto de los estudiosos ha emprendido lecturas "documentales" cuyas palabras clave son dictadura, globalización, medios de comunicación de masas y ciudad post-moderna. 


\section{ESCENA 2. EL LUGAR DEL PADRE (UN ARMARIO)}

De los libros que leen los narradores/ personajes de Fuguet, los de José Donoso tal vez sean los que despiertan pasiones más enconadas. La primera mención explícita a la obra de Donoso está en Mala onda (1991): diario de vida de Matías Vicuña, un colegial burgués que encuentra en la lectura de The Catcher in the Ride, de J. D. Salinger, un refugio donde resistir las condiciones de anomia suscitadas por la dictadura de Pinochet. En Mala onda, Matías debe rendir un examen sobre Casa de campo, novela que Donoso publica en 1978. La novela, el autor y su circunstancia producen desdén en el muchacho de ideas y hormonas alborotadas: "[el libro es] demasiado grues[o] y car[o], y no muy fácil de digerir" (182), [e]l autor es. . . chileno pero vive en España porque. . . este país es tan chico, tan chismoso y agobiante que el hombre no es capaz de escribir acá" (182; el destacado es mío).

En el examen, Matías apenas aprueba: mientras él lee la novela como un texto referencial sobre el incesto y la tortura (su lectura busca la concordancia plena entre $s u$ propia experiencia vital y el argumento del relato), su maestra, una militante de la izquierda chilena que lee la revista Apsi y usa una "chapita" del $N o$, le reprocha no haber ensayado una relación especulativa entre la obra de Donoso y el mega-relato de la dictadura militar. Matías falla: a diferencia de sus pares, no aprende a leer desde la alegoría. Por su manera impúdica de interpretar la novela, la maestra lo sancionará: "Te parece normal. . . [lo que ocurre en la novela]" (183).

¿Cómo se lee esta escena libresca? El protagonista de Mala onda alega que Donoso es "difícil de digerir" (183). La dificultad de lectura-deduzcoobedece a que el muchacho, asediado por "dilemas, serios traumas" (169), busca libros donde los desvíos de la disciplina familiar sean referencias a sus propios desvíos y no representaciones de las crisis (políticas y teleológicas) que se observan en el nivel macroscópico de la sociedad chilena de 1980; pues él, desde el gueto burgués de Vitacura, es incapaz de aprehenderlas: “... [me fastidio, no entiendo cuando] la Flora [su profesora] empieza a dictar cátedra. Analiza la novela. Explica lo de los primos... y por qué el sexo no es pornográfico. Habla del autoritarismo... y lo alegórico y la forma parabólica de ver el mundo" (183; los destacados son míos).

Dentro de la ley de valores de Mala onda, la alegoría es un tropo perverso: leer alegóricamente implica desnaturalizar los signos para considerarlos (a la manera de Walter Benjamín o Idelber Avelar), ruinas que testimonian la ausencia insoslayable de Dios (para Benjamin) y la caída de la ciudad letrada 
(para Avelar). La alegoría, por ende, instala un pacto de interpretación que sanciona aquellas lecturas privadas, casi secretas, que hacen poco caso de los discursos de la clase, la historia y la nación. Un ejercicio de lectura privada, por ejemplo, es el que realiza Matías cuando se enfrenta a The Catcher in the Ride; un texto que, al ser ignorado por los insurgentes chilenos, aún se deja leer sin más responsabilidad que el propio goce de perderse/ encontrarse a sí mismo: "[a]noche conocí a Holden Caulfield. Fue algo químico, absolutamente arrollador. No podía creerlo. Ya no estaba tan solo, me sentí menos mal. . . Había encontrado un doble. . ." (205), “[e]sto me asusta porque Holden es un gran tipo, lo quiero a cagar" (206).

La alegoría -si se me permite el juego de palabras- trabaja como un "armario": espacio donde los protocolos de lectura mecánica nos obligan a renunciar al goce (del cuerpo) del texto: en Casa de campo "nada es lo que aparenta," pues, "tanto por lo que se deduce de la lectura, como por lo que conversamos en clase, parece claro que Donoso está hablando del Golpe de Estado de 1973 [-insiste la maestra]" (183; el destacado es mío) ${ }^{8}$. Cual lector de Barthes, Matías considera que el goce (de la escritura, de la lectura) solo es posible cuando el texto se desnuda ante los ojos del lector como una zona de imprevisión donde el determinismo contextual sea neutralizado, "las cartas [de los modelos que rigen la escritura/ lectura] no estén echadas" y "haya juego [interpretativo] todavía" (Barthes 12). Por el contrario, un texto escrito/ leído fuera del goce (es decir, encerrado en el armario de la alegoría [nacional]), "se diría que [apenas nos] murmura" (Barthes 13). Y -aún más- "ese texto murmullo [sería, por su falta de imprevisiones,] un texto frígido" (Barthes 13).

Con todo, me parece que esta opinión subyace los dos epitafios que Fuguet (ahora hablando como escritor) le dedica a Donoso en uno de sus últimos

8 El discurso de Matías es, a fin de cuentas, una refutación del axioma determinista de Frederic Jameson: "[a]11 third-world texts are necessarily. . . allegorycal," razón por la cual debemos leerlos como ". . . national allegories" (69; el destacado es mío). Y no solo eso. Dos años después de la publicación de Mala onda, en 1993, Fuguet volverá a atacar a los intelectuales metropolitanos que insisten en leer solo aquellos discursos hispanoamericanos que aceptan ser decodificados como alegorías de la barbarie o el subdesarrollo: "[1]os países consumidores de cultura tendrán que dejarnos de ver como lugares exóticos y empezar a leer historias que registren el choque [multicultural], que exploren nuestras influencias de España pero también de Miami, que delaten que, culturalmente, estamos tan al día como ellos, que más que isla somos parte del todo" (Primera 146). 
libros, la colección de crónicas Apuntes autistas: "Donoso cerró una puerta y se encerró a sí mismo dentro. ..” (196), en la época de Mala onda, “Donoso me parecía complicado y plagado de casas sin ventilar" (275).

\section{ESCENA 3. LUGARES SIN LÍMITES (LIBROS Y JARDINES)}

Si el Donoso de Casa de campo es desdeñado por el carácter "frígido" de su retórica, el Donoso de las crónicas y novelas "realistas," en cambio, cuando no es elogiado, es expresamente mimado -discutamos, ahora, esta tesis.

En la compilación de artículos de prensa Primera parte: crónicas, columnas y literatura instantánea (2000), el narrador -Fuguet, esta vez, autorepresentado como periodista ${ }^{9}$ - celebra la aparición de Artículos de incierta necesidad, volumen de escritos periodísticos que Donoso publica en Chile, en 1988. "Al finalizar el libro, y después de subrayarlo entero" (9), Fuguet entrevé que dichas crónicas son más libres, pasionales y vigorosas que las "novelas-armario" que padeció Matías en Mala onda. No solo eso, mientras subraya el mentado volumen tirado junto a las tumbas de los jesuitas que fundaron Georgetown University, se permite confesar que: "yo también quiero tener un libro así. Quiero además, estar aquí, presente, vivo, para disfrutarlo y, sobre todo, para armarlo" (11). Pues bien, Fuguet desea ser como Donoso, gozar como Donoso, pero como ese Donoso cronista, sin máscaras, que descubre en la inmensidad ilimitada de los prados que rodean las bibliotecas de Georgetown, muy lejos de este Chile "tan chismoso y agobiante" desde donde yo escribo estas líneas ${ }^{10}$. ¿Lo consigue? -Para poder responder es preciso, antes, hacer un poco de historia.

9 Desde la introducción, el texto se presenta como una autobiografía profesional donde Fuguet muestra, a través de su trabajo periodístico, cómo llegó a ser lo que él es: "[e]ste libro es básicamente eso: mi primera parte. Como periodista, como escritor, como persona" (11).

10 Contrástense las escenas de lectura de Casa de campo y Artículos de incierta necesidad, respectivamente. La novela, leída en una sala de clases y bajo vigilancia tutelar de la maestra de escuela (representación de una cultura signada por el autoritarismo del Estado y el maniqueísmo de los ciudadanos), se queda atrapada en el armario, razón por la cual apenas se oye su "murmullo frígido". Los Artículos. . ., en tanto, leídos fuera de Chile (en USA), en un jardín (cuyos límites están más allá de la percepción del ojo humano), y sin más testigos que las lápidas que recuerdan a los antiguos inmigrantes jesuitas (los sacerdotes están muertos, ya no son ojos vigilantes), se gozan. Y, recuérdese, que hay goce allí donde escritura y 
Cuando Bolaño arremete en contra de la nueva narrativa chilena (fenómeno editorial de la década de 1990, del que Fuguet es su long seller), no vacila en definir al autor de Mala onda y sus congéneres como herederos auto-proclamados (y espurios) del testamento literario de Donoso, El jardín de al lado (1981), una de sus tres únicas buenas novelas que, para colmo de males, los "donositos" (apelativo irónico por el que Bolaño designa a Fuguet y los demás estudiantes del taller de Donoso) no han entendido en lo más mínimo. "Donoso escribió tres libros buenos" (Bolaño 99); uno de ellos, "El jardín de al lado que se ofrece como juego y testamento" (99), "[m]ejor sería que [los "donositos"] dejaran de escribir y se pusieran a leer. Mucho mejor” (101).

Si se me permite el atrevimiento, creo que Bolaño, raramente, no percibe la "estrategia" de Fuguet. En las líneas que siguen procuraré demostrar que este testamento literario que es El jardín de al lado es recuperado por Fuguet: no en el nivel de la anécdota sino, más bien, como poética de la construcción de una masculinidad otra (Los narradores/ personajes de Fuguet conseguirían ser como Donoso).

Pero, antes de cualquier disquisición, ¿por qué a los narradores/ personajes de Fuguet les podría interesar El jardín de al lado? El jardín de al lado -me permito una apresurada reseña- tiene seis partes (numeradas en arábigo), todas contadas en primera persona; en las cinco primeras, Julio Méndez testimonia su fracaso en la empresa de convertirse en el Marcelo Chiriboga de las letras de Chile y, lo más "llamativo," su fascinación por Bijou, "un muchachito que no aparentaba más de catorce años, vestido de jeans y camiseta blanca" (52). En la parte final, el narrador/ protagonista confiesa ser una mujer escritora que, literalmente, imposta la voz de un hombre.

El jardín de al lado -y esta es mi respuesta a la pregunta recién planteadamarca, a ojos de un narrador/ personaje de Fuguet (como Matías de Mala onda), un punto de inflexión en la escritura de Donoso. En él, quien habla ya no es el narrador que figura el cuerpo de los peones como alegorías del trabajo artístico ("El hombrecito" [1971]) ${ }^{11}$. Tampoco es el narrador omnisciente que mienta un prostíbulo que, a fin de cuentas es el infierno (El lugar sin límites

lector se buscan/ coquetean a tientas, sin protocolos preconcebidos ni miradas inquisidoras de terceros (Cfr. Barthes 12-13).

11 Sergio Holas Véliz afirma que el hombrecito del relato donosiano no es "ni hombre ni niño, es [más bien] figura de una posición intermedia. . . y que en este texto toma la forma 
[1966]) ${ }^{12}$. En El Jardín de al lado, quien habla hilvana un discurso (que invita a ser leído como) referencial ${ }^{13}$ : la pulsión sexual que va de Julio a Bijou no es, como en El lugar sin límites, una alusión a lo numinoso; muy por el contrario, es un discurso que busca la complicidad del lector en su deseo por el cuerpo del otro: "[b]ajo sus rizos dorados de angelo musicante me saludó con una sonrisa luminosa en la oscuridad" (52), "[s]alí tras ese mancebo cuya cabeza rapada y pómulos altos lo hacían asemejarse a una máscara egipcia" (80), "[e]ntré con el muchachito en la estrecha cabina [telefónica]: su talle delicado quedó perturbadoramente junto al mío" (86), “. . . estaba allí ese delgado cuerpo calculador y sabio, casi tocando el mío, me di cuenta, esperaba que yo diera el paso en falso de acercarme un milímetro más" (87), "[s]í -respondí como un niño que confiesa una travesura" (88).

La enunciación de este relato presta sus estrategias a una serie de escritos de Fuguet. Ya en "Deambulando por la orilla oscura", relato breve fechado en 1987 y publicado en su primera antología de cuentos, Sobredosis $(1990)^{14}$, el narrador se revela como un atento lector, conocedor de las triquiñuelas de Donoso. La relación entre el cuento de Fuguet y la novela de Donoso es doble: entre ambas hay similitudes tropológicas y-lo más relevante-idénticas estrategias meta-discursivas por las cuales los narradores (en riesgo, quizá, de ser considerados alter-ego de los autores empíricos), se excusan ante la censura de "este país tan chico, tan chismoso" de decir lo que dicen (elogios al cuerpo masculino adolescente). Compárense las aproximaciones, de uno y

del equilibrista en la cuerda floja que a su vez es una metáfora del escritor que teje el nudo que hace posible entender imaginariamente los vacíos de la experiencia" (139-40).

12 Al iniciar su lúcida lectura sobre El lugar sin límites, Rodrigo Cánovas repara que “[e]l epígrafe nos conmina a interpretar esta obra como una alegoría del infierno: está debajo del cielo, en la tierra, es el lugar donde vivimos" (54).

13 Adriana Valdés, en su reseña de la novela, indica que: "El Jardín de al lado le hace una venia a Chatanooga Choo Choo, la primera de las Tres novelitas, y en un polo opuesto al de El obsceno pájaro de la noche (1970) y Casa de campo (1978). En el conjunto de las narraciones del autor, este 'tono menor' podría definirse provisionalmente como el de las que presentan personajes aparentemente menos esperpénticos, más 'reconocibles,' y que recogen un material más inmediatamente testimonial" (431).

14 "Deambulando por la orilla oscura" - en términos fílmicos- es la representación escrita de un plano-secuencia cinematográfico: el ojo-cámara del narrador persigue al Macana, un teenager recién fugado de una exclusiva clínica de rehabilitación que, después de haber asesinado a puñaladas a un inmigrante coreano, cruza los pasillos un centro comercial para, finalmente, lanzarse al vacío. 
otro narrador, al cuerpo masculino adolescente. Del Bijou donosiano sabemos que: "se rapó la cabeza en protesta" (79), que cautiva por "el desafío perverso de sus ojos claros" (80), que cuando deambula entre la multitud adolescente lo "acogieron. . . acentos catalanes. . . expresiones de afecto. . . de aprecio o admiración. .." (81), que algunos lo consideran "un pibe vicioso, capaz de cualquier cosa" (83), que se sus ademanes evocan a los kooks que celebran la canción de David Bowie (92), que "en el escaparate que sirve de espejo veo su aureola de pelo rubio" (136), que sus "Adidas. . [relucen] encima de la mesa como un obsceno objeto pop creado por Andy Warhol" (165).

Del Macana, de Fuguet, en tanto, sabemos que: tiene una "desordenada melena que cuelga sin ánimo" (10), que seduce "con su pinta de guerrero de pandilla americana, con ese aro chacal en forma de calavera" (10), que cuando entra al Apumanque "sintió la mirada de todos" (11), que de él se dice que "[e]s un reventado" (11), que "[e]l pendejo se las trae" (11), que sus gestos recuerdan los versos de Lou Reed ("It's hard to give a shit these days" [10]), que "[a]l acercarse a las puertas de vidrio automáticas. . . pudo ver. . . su reflejo. . . . con ese tipo de belleza que solo surge después de la pelea" (10), que "estiró sus viejos Levi's hasta dejarlos lisos y tirantes" (10).

Las similitudes retóricas son evidentes; ambos son cuerpos púberes (Bijou confiesa "dieciséis años. .." [52] y Macana, "trece. . . vividos a fondo" [11]); cuerpos rebeldes (Bijou dice a un corro de exiliados que "Chile está pasado de moda" [56] y Macana cree que los santiaguinos son "parásitos que vegetaban" [11]); cuerpos objetos de serigrafía pop (Bijou calza "jeans. . . Adidas" [57], Macana, Levi's); y -lo más destacable- cuerpos "agresivos" (Bijou destella una "malvada suciedad rubia" [80] y Macana "se veía aún más fuerte. . . como si lo siguiera una horda de ultraviolentos y él fuera el líder indiscutido" [10]). En un gesto novedoso para la novelística chilena, ambos ungen como objeto de admiración cuerpos de adolescentes masculinos que dialogan con referentes de la tradición anglosajona: el bello marinero del Billy Budd (1891), de Herman Melville (en el caso de Donoso) ${ }^{15}$, y los

15 El cuerpo de Billy Budd es descrito por Melville en términos de belleza divinia ("[a] superb figure, tossed up as by the horns of Taurus against the thunderous sky. .." [44]) que, en sí misma, acarrea la perversion de Luzbel ("[The handsome sailor is] the direct reverse of a saint" [74]). En Bijou -recordemos- Donoso ve "[r]izos dorados de angelo musicante" (52), bajo los que se oculta su "malvada suciedad rubia" (80). 
pandilleros de Rumble Fish (1975), de Hinton (en el caso de Fuguet) ${ }^{16}$. Por el contrario, en Chile, los narradores acostumbran a invocar el deseo por cuerpos de adolescentes feminizados o exóticos, tal como los mienta la novela francesa moderna, El inmoralista (1902), de André Gidé; piénsese, sin ir más lejos, en el acólito gitano que seduce al párroco vasco en Pasión y muerte del cura Deusto (1924), de Augusto D'Halmar.

Desde una perspectiva meta-discursiva, la manera en que Julio Méndez, el narrador de El jardín de al lado, explica su atracción por Bijou es replicada por los narradores-personajes construidos por Fuguet. Julio dirá que "Bijou se estaba postulando. . . [en mi caso] como Rimbaud para el matrimonio Verlaine-Mathilde" (80); no obstante, “[d]e repente comprendí. . . que no era tan sexual mi atracción por Bijou sino otra cosa, un deseo de apropiarme de su cuerpo, de ser él, de adjudicarme sus códigos y sus apetitos, mi hambre por meterme dentro de la piel de Bijou era mi deseo porque mi dolor fuera otro; otros que yo no conocía o había olvidado; en todo caso, no mi código tiránico ni los dolores que me habían desecho" (87). Y, más adelante, aclara: "[el sexo] [c]omo complemento, tal vez sí, pero no en primer lugar" (87).

Recapitulo la precisa estrategia del narrador: Julio dice su deseo con novedosas palabras que bien podrían ser las de Melville (Bijou es, como Billy Budd-marinero, un ángel perverso [52, 80]), traduce la desmesura de su deseo a un código "familiarmente aceptado" por el oído de sus escuchas (le dice a Carlos Minelbaum que Bijou es, más bien, Rimbaud-poeta [80]), y, una vez instalado en el código de los pares, esboza una lectura naturalizadota (en verdad, "lo mío" no es búsqueda del goce sino ejercicio terapéutico [87]).

La explicación de los narradores de los relatos de Fuguet se ampara en la misma lógica aprendida del padre. En Apuntes autistas, el cronista -al reflexionar sobre el lugar que ocupan los narradores-personajes adolescentes en su propia narrativa- se preguntará por qué lo seduce tanto Almost Famous (2002), filme de Cameron Crowe que retrata la vida de las bandas de rockglam de la década de 1970, aunque desde la perspectiva de "un chico de quince años que se va de gira con un grupo de rock" (128): William Miller. Tras elogiar la construcción del personaje-adolescente por su pureza y por

16 Hinton y Fuguet -por ejemplo- comparan a sus héroes con la figura pop de Rusty James. En la novela de Hinton leemos: "I was sitting on the beach and he come up to me and said 'Rusty James'?” (1). En el relato de Fuguet, el narrador apunta: “[Macana,] un héroe, un huevón dispuesto a todo, un Rusty James chileno” (9). 
su ternura ("[1]e tocará a cualquiera que ha sido fan. . . que ha apostado por un clan de iguales" [128]), el cronista procede a compararlo, súbitamente, con el protagonista de las películas mayores de Francoise Truffaut: "Antoine Doniel, el personaje que no inventó François Truffaut porque personajes como esos no se inventan, se comparte" (128). Parafraseando al maestro francés, el cronista concluirá que el William, de Crowe -y por extensión, los adolescentes de sus ficciones- son los alter-ego de sus creadores: "El filme de mañana [y por extensión las narraciones] será aún más personal que una novela autobiográfica; será como una confesión. . . . El filme de mañana se parecerá a la persona que lo realizó. . . . El filme de mañana será un acto de amor" (128-29).

Al igual que en la escritura de Donoso, hay un objeto de admiración (William, un muchachito de ficción anglosajona [128]), una traducción de esa admiración a una retórica francesa, más cercana a los escasos lectores criollos (William es, a fin de cuentas, Antoine [128-29]), y una interpretación sobre el propio trabajo que clausura cualquier lectura equívoca (el adolescente de las grandes ficciones es un alter ego del autor, no un otro [129]).

Con todo, me parece que aquel lector voyeur, al que invoco en este ensayo, notará que en la fijación por la adolescencia hay más que un gesto narcisista (un yo que elogia a su alter-ego). Es evidente que, en la primera narrativa de Fuguet, el único espacio donde es posible la complicidad afectiva con el otro es en la adolescencia, en la unión cómplice entre cuerpos de hombres adolescentes. Para respaldar esta afirmación, repasaré algunos pasajes de la citada Mala onda ${ }^{17}$. En Mala onda, Matías (el protagonista), se encuentra agobiado por las dudas: “¿Qué hacer? ¿Virarse? ¿Mandar todo a la cresta? ¿Escapar?” (169). Quizá por eso, Matías confiesa afecto solo dos veces en la novela. La primera vez, hacia un compañero de curso (Nacho) ${ }^{18}$ : "Yo podría dominarlo si quisiera; es el típico gallo al que le cuesta tomar una decisión por sí mismo. Siempre me anda pidiendo consejos. A veces se los doy. Supongo que lo quiero pero nunca se lo diría porque nada que ver nunca tan maraco" (39). El Nacho -apostilla Matías- "es un surfista consumado y baila zamba como nadie" (39). Salvo halagos y descripciones del físico de su amigo,

17 Dicho sea de paso, el relato "Deambulando por la orilla oscura," antes comentado, fue el primer borrador de Mala onda (Apuntes 310).

18 La segunda muestra de afecto, como dije, es hacia Holden, el protagonista de The Catcher in the Ride, de Salinger. 
Matías guarda silencio porque: "si uno anda analizando las amistades, seguro termina más que solo" (39).

Matías, pese a las restricciones auto-impuestas (el afecto es cuestión de "maracos"), expresa un fuerte sentimiento de posesión hacia Nacho. En plena fiesta de colegiales, el narrador-protagonista se excita con la posibilidad de iniciar a su amigo en el consumo casual de cocaína. Sorprendido por el rápido aprendizaje de su camarada, exclama: "Estás al día, veo. Muchas películas" (75). El aludido responde: "No, el Papelucho [otro "conocido"] me enseñó" (75). Matías se irrita: "Esto me cae como las huevas" (75), “¿Así es que esta no es tu primera vez?" (75). Nacho replica irónico: "No, no soy virgen. Espero no decepcionarte" (75). La escena finaliza con una sugerente coreografía: "Yo me acerco [al Nacho], él abre la boca. Le paso el tubo y lo aprieto un poco hasta que algo de pasta se acumula en su lengua" (76).

Servirse de este tipo de escenas para afirmar que Mala onda es una novela de asunto queer, sería un ejercicio de lectura infundado o superficial. Más relevante parece constatar que los narradores/ personajes de Fuguet consiguen construir un espacio de libertad análogo al que consigue Donoso en sus crónicas y novelas "realistas." En la narrativa de Fuguet, este espacio de libertad se construye a partir de la superposición de planos: sus narradores/ personajes profieren enunciados "rectificadores" que evitan la suspicacia de los censores de "este país chismoso y agobiante que no lo deja escribir" ("[s]upongo que lo quiero pero nunca se lo diría. . ." [39]). No obstante, a ojos de los entendidos, estos enunciados hétero-normativos se desvanecen por el lugar donde son dispuestos: una escena coreográfica donde el cuerpo dice todo aquello que la lengua de las familias criollas sanciona (" $[\mathrm{y}]$ o me acerco, él abre la boca. .." [76]). La de la narrativa de Fuguet es—en síntesis — una lengua doble: así como conoce los mecanismos para "enmendar" sus desvíos, también conoce las tácticas para "gozar" más allá de las reglas ${ }^{19}$.

19 En la escritura del Fuguet se percibe el goce -en el sentido que Barthes imprime al término-que desata el cuerpo adolescente en el ojo de los narradores-personajes. No obstante, no se trata de una atracción suscitada por las carácterísticas físicas de los muchachos referidos (Macana, Matías o Nacho). Se trata, más bien, de un goce que surge cuando el ojo de esos personajes-narradores comprende -al igual que la ensayista australiana Germaine Greer-que el del adolescente es un cuerpo inacabado; un cuerpo que, aunque ya conoce (y también puede) interpretar el rol que la sociedad le encomienda, todavía se permite, consciente o inconscientemente, el juego del desvío: "[a] boy is a male person who is no longer a child but not yet a 


\section{ESCENA 4. MATAR AL PADRE (EN LA ESCENA DE LA ESCRITURA)}

El jueves 12 de diciembre de 1997, aparece en las librerías de Santiago Tinta roja, la última de las tres novelas publicadas por Fuguet en la década de $1990^{20}$. El texto (lanzado en "Los Braseros de Lucifer", un restaurante del otrora "burdelesco" barrio santiaguino de San Diego), desconcierta a la crítica periodística, pues el narrador pop "abandona la [sofisticada] Av. Kennedy" (Silva 42) y los anglicismos "livianos como paquete de barquillo" ("Fuguet" 38), para adentrarse en "ese sub-mundo santiaguino" (Poo 33), de los "prostíbulos y hoteles galantes, bares, picadas y cocinerías, salones de pool y botillerías, topless y quintas de recreo y boites[,] y todo tipo de comercio barato...." (Tinta 76).

Con la aparición de Tinta roja, la crítica celebra que, al fin, "Fuguet [joven promesa de las letras chilenas] subió varios peldaños en su ascendente [pero hasta ese entonces light ] carrera literaria" ("Fuguet" 38). El propio autor confesará en rueda de prensa que el vuelco estilístico obedece a la seducción que sobre él ejerce la novela lumpen: movimiento de la literatura criolla, también conocido como de los malditos o ejes de la pícara chilena, que él descubre hurgueteando en las "librerías de viejos"-lejos de la academia y del taller de Donoso ${ }^{21}$.

En todo caso, de los novelistas lumpen, el que más seduce a Fuguet es Alfredo Gómez Morel, autor de El río (1962): historia de un "[h]uérfano hijo de prostituta, 'pelusa' del río Mapocho, violado por pandilleros, delincuente juvenil, lanza. .." (Fuguet, "Presentación” 21). Su obsesión por Gómez Morel lo lleva a escribir un texto que leerá en el re-lanzamiento de la novela (1998) y que, más tarde, será anexado como una segunda "Presentación" de este "clásico de la miseria" -como lo bautizó Neruda en su prólogo a la edición francesa de este libro. "Llegué a El río" -rubrica Fuguet- "investigando

man" (13). Siguiendo a Greer, nótese que a los adolescentes desviados mentados por Fuguet en Sobredosis y Mala onda, aún les restan algunos años de escuela rectificadora.

20 Su siguiente novela, Las películas de mi vida, aparecerá recién a fines del 2003.

21 Se trata de autores que desde finales de la década de 1950 auto-editan (en papel roneo) novelas sobre el hampa, ambientadas en los lupanares de los barrios Franklin y San Diego, y protagonizadas por cafiches y lanzas que dialogan en vívida clave coa. Entre los autores más destacados de esta "escuela," se anotan Armando Méndez Carrasco, con Chicago chico, y Luis Rivano, con Esto no es el paraíso. 
material que. . . se convertiría en Tinta roja, novela. . . que le debe mucho a este movimiento. .." (20).

En Tinta roja, Alfonso Fernández (escritor fracasado) recuerda su práctica profesional en la sección de crónica roja de un tabloide amarillista, en plena década de 1980: El Clamor: diario masivo y popular. Allí, al alero del "procaz, desalmado y feroz" (66) Saúl Faúndez - cuya máxima es que "[e]1 periodismo, como la prostitución, se aprende en la calle" (71)- reconoce aquella ciudad que explora la novela lumpen.

Desde la perspectiva de este ensayo (discusión sobre la manera en que Fuguet cita la tradición letrada chilena en función de la construcción de una nueva masculinidad), lo más relevante de la novela es que el recuerdo de Alfonso restituye un canon literario chileno anclado en los márgenes: ni Donoso ni Edwards Bello ni Edwards; sí José Santos González Vera (un capitulo de Tinta roja que habla sobre la anomia se titula "Vida de santos"), sí Alfredo Gómez Morel, sí Nicomedes Guzmán (una sección de la novela se llama discipularmente "La sangre y la esperanza"), y sí Manuel Rojas (de su Hijo de ladrón viene uno de los epígrafes).

En la escena de la escritura, el discípulo (Fuguet) niega al padre (Donoso) ${ }^{22}$. El hijo (Fuguet) propone reemplazar a las "viejas decrépitas" del imaginario paterno (donosiano) por los pelusas del Mapocho (esos mismos que ultrajan al narrador de El río). Pese a sus instintos parricidas, la escritura del "hijo" no logra despegarse de los modelos "paternos". El reconocimiento al padre que el enunciado niega, la enunciación lo devuelve como un texto fantasma que merodea la sintaxis de la novela. Veamos, pues: a diferencia de lo que ocurre en la novela lumpen, el narrador protagonista de Tinta roja participa de manera vicaria de la escena del hampa. Su contacto con violaciones y ultrajes se produce desde la perspectiva del periodista que observa con distancia o a través de las portadas de los tabloides - es curiosa la cantidad de errores referenciales que se encuentran en la novela ${ }^{23}$. La imposibilidad de ascender a los arrabales es rubricada, finalmente, por un arsenal retórico

22 La relación filial entre Donoso y Fuguet se remonta a 1988. Fuguet aprende a escribir en el taller de Donoso; mientras el hijo díscolo lee a Bukowsky, su padre le reprocha su conocimiento parvulario del realismo ruso. En la dedicatoria de Mala onda se lee: “A. . José Donoso, por lo de Dostoiewski. . ..” (297).

23 Por ejemplo, sabemos que la anécdota transcurre en 1988, pues, los personajes comentan pasajes del Festival de Viña de ese año (Cfr. 302); no obstante, esos mismos personajes 
que le debe menos a Gómez Morel (padre putativo) que a los primeros cuentos de Donoso (padre negado). Compárense párrafos reveladores de la insistencia de la voz paterna:

... la agitación maloliente de las cocinerías alterna con la tranquilidad de las tiendas de libros de segunda mano y con el bullicio de los establecimientos donde hombres sudorosos horman y planchan. ... Todo el mundo se arremolina en torno a los puestos de fruta... . Abismos de oscuridad o de luz caen entre los rostros que se aglomeran en torno al charlatán vociferante (Donoso, "La China" 249).

El pasaje Rosas es una suerte de conventillo multicolor con entradas a ambos lados. . . La cocinería "Rosita" se ubica en plena Vega, entre los puestos de frutas, las carnicerías y un local especializado en aceitunas y pickles que expele un implacable aroma a vinagre (Tinta roja 134-35).

Llegan a la estrecha calle y la imagen remite a Bombay. ... Franklin está convertido en un mercado persa ambulante y la muchedumbre bloque el paso. Cientos de comerciantes informales que se confunden con los mendigos vociferan sus camisas estampadas. . . . Un carro destila vinagre y las aceitunas parecen pasas de tanto esperar al sol. ... Fernández huele el denso aroma de la pimienta, el comino, el legendario aliño negrita (Tinta roja 153).

En primavera el sexo despierta, un pelusa con hambre sexual se convierte en un monstruo. Nos juntábamos al amanecer, elegíamos un jefe de expedición y nos íbamos a la cloaca en busca de carne. ... Continuaba la inspección, el jefe tocaba las nalgas y miraba las piernas hasta que se formaba un criterio sobre la mercadería. Se hacía la selección: los buenos a la izquierda, los malos a la derecha. Se invertían ciertos órdenes religiosos. Aullando como horda primitiva nos lanzábamos sobre ellos (Gómez Morel 203-4).

Ni Donoso y ni Fuguet penetran la superficie del arrabal; ambos lo conciben como un cuadro orientalista ("La China" y "Bombay," respectivamente), donde abundan imágenes de "cocinerías" atestadas de una "muchedumbre

escuchan, aún en la clandestinidad, los primeros "casetes piratas" de Los Prisioneros -en 1988, Los Prisioneros ya eran superestrellas editadas en todo el continente (Cfr. 235). 
vociferante" y "maloliente". Gómez Morel, en cambio, se describe a sí mismo como un sabueso a quien le importa menos el colorido de mercados persas y conventillos, que su propia "hambre sexual" (203) y los aullidos de su "horda primitiva" (204).

El diálogo entre Tinta roja y El río puede ser leído de dos maneras: literalmente, como un intento fallido de Fuguet por hacer ficción sobre un espacio poco, para él, conocido. Sin embargo, de manera más libre y especulativa, el affaire es llamativo por la manera en que el autor justifica su fascinación por los "reyes del hampa" ("Hacía mucho tiempo que no me entusiasmaba tanto [con un libro]" ["Presentación" 21]).

A través de una alegoría familiar, explicaré la manera por la que Fuguet presenta a Gómez Moral: el muchacho quiere alejarse de las normas de la casa paterna (no quiere escribir como el Donoso barroco, alegórico), pero, al mismo tiempo, teme la reprimenda castradora de la crítica periodística y de los lectores-fans adolescentes acostumbrada a sus relatos pop. Desconfiado, invitará a sus nuevos camaradas (los novelistas lumpen encabezados por Gómez Morel) a participar de su escena de la escritura; para evitar las reprimendas de sus pares (desdeñosos de los ejes de la picaresca chilena), mentirá sobre el origen de sus nuevos camaradas: insistirá en que se trata de textos más próximos al decadentismo beat estadounidense o a la novela urbana inglesa de finales del siglo XIX, que a las zonas oscuras de una contra cultura chilena. Presentará a El río como novela del "under" santiaguino (22), o como un Oliver Twist escrito en la ribera del Mapocho (22). Gómez Morel, por si fuera poco, será admitido en su biblioteca como un Bukowsky santiaguino. O, si se prefiere, como un Richard Price ${ }^{24}$.

Al igual que Mala onda (y más allá de las referencias al hampa), Tinta roja insiste en dos puntos cardinales de la escritura de Fuguet: (1) el afecto y el desvío solo son aceptados como fenómenos literarios canonizados por la "institucionalidad" literaria (en Mala onda, a través de la lectura de Salinger

24 Un año antes del lanzamiento de Tinta roja, Fuguet publica tres artículos en la Zona de contacto (suplemento juvenil-cultural del diario El Mercurio difusor de la literatura del grupo "McOndo" y la cultura de la Generación X), donde presenta a estos ejes de la picaresca como precursores del pulp fiction criollo: "Ficción pulpa o nuestra propia literatura barata", "Armando Méndez Carrasco: cachetón y coprolálico" y "Alfredo Gómez Morel: río, río". Estos tres artículos se encuentran reimpresos en el citado volumen Primera parte (121-23, 124-26, 127-29). 
o de las comparaciones con Truffaut, y en Tinta roja, a través de la lectura de un Gómez Morel inmortalizado como un beat avant la lettre). (2) La relación con el otro - especialmente el cuerpo masculino-se consuma siempre a través de una lengua que, no es otra, que la aprendida del padre, José Donoso.

\section{ADENDA}

La relación entre Fuguet (autor) y Donoso (autor) replica la lógica de los conflictos entre sus respectivos personajes. Un relato popular, por todos conocido, me permitirá justificar esta afirmación y poner puntos suspensivos a este ensayo.

En la versión freudiana del mito de Edipo, un padre es despojado de sus derechos por un usurpador advenedizo, mientras el hijo se muestra incapaz o poco interesado en vengar la afrenta (recuérdese a Hamlet, incapaz de vengar la muerte de su padre). Donoso (una de las cumbres de las letras chilenas del siglo XX y maestro tallerista de esa nueva narrativa chilena donde se sitúa Fuguet), es denostado por Roberto Bolaño (un expatriado chileno que alcanza fama mundial desde su exilio catalán): “[1]a [única] herencia de Donoso es un cuarto oscuro. . . En el gran teatro de Lezama, Bioy, Rulfo, Cortázar, García Márquez, Vargas Llosa, Sábato, Benet, Puig, Arenas, la obra de Donoso automáticamente se desplaza a un segundo plano y empalidece" -arremete Bolaño (100).

Fuguet, discípulo aventajado de Donoso, se hace cómplice de la agresión: "Lo leí [lo que dijo Bolaño], me reí. . . . Bolaño se transformó en un personaje y sigue siendo coherente" ("Literatura"). Además, celebra que "[s]u prosa es fácil, precisa, limpia, no barroca [como la de Donoso]" (“Autor" 9). Según Freud, el hijo no vengará al padre porque, inconscientemente, sabe que el padre detenta un bien que para él permanece vedado (Hamlet no mata al asesino de su padre porque ese asesino mató, a fin de cuentas a quien le usurpó a su madre).

En esta versión criolla del mito, ¿qué es aquello que el hijo envidia del padre? Supongo que aquello que los personajes de Fuguet envidian es ese espacio de autorrealización personal creado por Donoso a través de su escritura (alegórica, a veces, o plagada de acertijos literarios, otras), ese "lugar sin límites" que le permitió burlar las censuras de este país "tan chismoso", esa íntima escena de escritura que no compartió con ninguno de sus discípulos y donde, por lógica consecuencia, nadie más pudo entrar. Desde esta posición, 
parece urgente releer el epitafio que Fuguet dedica a su maestro (Donoso) como representación de los fantasmas que acechan la escena de su propia escritura: "[los libros de] Jorge Edwards [por ejemplo] le ha[n] pavimentado el camino a muchos [novelistas jóvenes]. Mientras Donoso cerró una puerta y se encerró a sí mismo dentro. ..." (196).

\section{BIBLIOGRAFÍA}

“Fuguet no estaba muerto”. El Mercurio. 18 Dic. 1996: C38.

Alonso, María Nieves. "Alberto Fuguet, un (in) digno descendiente de una buena tradición”. Acta literaria 29 (2004): 7-31.

Barthes, Roland. El placer del texto. 1973. El placer del texto y Lección inaugural. Trad. Nicolás Rosa. México: Siglo XXI, 2000. 9-109.

Bolaño, Roberto. Entre paréntesis: ensayos, artículos y discursos (1998-2003). Barcelona: Anagrama, 2004.

Butler, Judith. Undoing Gender. New York: Rouledge, 2004.

Cánovas, Rodrigo. Sexualidad y cultura en la novela hispanoamericana: la alegoría del prostibulo. Santiago: Lom, 2003. 53-68.

Donoso, José. “China”. Cuentos. Barcelona: Seix Barral, 1971. 247-54.

El jardín de al lado. 1981. Santiago: Alfaguara, 1996.

Fuguet, Alberto. "Deambulando por la orilla oscura", "Los muertos vivos" y "Pelando a Rocío”, Sobredosis. Santiago: Planeta, 1990. 9-15, 29-45, y 47-77. "Presentación. Alfredo Gómez Morel y El río: el clásico de la miseria". El río. De Alfredo Gómez Morel. Santiago: Sudamericana, 1997. 19-24.

“Un autor muy contemporáneo". N 208 (2007): 9. Apuntes autistas. Santiago: Aguilar, 2007. Las películas de mi vida. Santiago: Alfaguara, 2003. Mala onda. Santiago: Planeta, 1991. 2000 . Primera parte: crónicas, columnas y literatura instantánea. Santiago: Aguilar, The Movies of my Life. Trans. Ezra E. Fitz. New York: Harper Collins, 2003. Tinta roja. 1996. Santiago: Aguilar, 2001.

Gómez Morel, Alfredo. El río. 1962. Santiago: Sudamericana, 1997.

Greer, Germaine. The Beautiful Boy. New York: Rizzoli, 2003.

Hinton, S. E. Rumble Fish. 1968. New York: Bantam Dubleday Dell, 1989.

Holas Véliz, Sergio. Racionalidad e imaginación: transposiciones del cuerpo y de la mente en los cuentos de José Donoso. Madrid: Pliegos, 2001. 
Jameson, Frederic. "Third-World Literature in the Era of Multinational Capitalism". Social Text 15 (1986): 65-88.

Melville, Herman. Billy Budd. 1891. Billy Budd and Other Stories. London: Penguin, 1998. $1-90$.

Poo, Ximena. "Alberto Fuguet indaga los bajos fondos". La Época. 15 Dic. 1996: 33.

Silva, Ana Josefa. "Tinta roja: la novela en que Fuguet abandona la Av. Kennedy: 'Quise hacer un libro más chileno" ". La Segunda. 17 Dic. 1996: 42.

Valdés, Adriana. "El jardín de al lado de José Donoso”. Mensaje 301 (1981): n.p. 